\title{
Agit-Prop y Análisis: \\ El arte políticamente comprometido como inspiración para la práctica clínica contemporánea ${ }^{1}$
}

\author{
Andrew Samuels ${ }^{2}$ \\ IARPP, Londres, U.K.
}

Este trabajo nos muestra que un profesional comprometido tiene muchas posibilidades de servir a la comunidad con una forma de vida políticamente comprometida, tanto como persona como en cuanto profesional. Principalmente, puede, como un "espectador activo" participar en los argumentos de la vida personal y social, sin identificarse con un héroe, sino como un agente. Es el uso de lo que denomina "agit-prop", arte o escenificación provocadora, que a través de un distanciamiento del drama humano personal nos permite ver más en perspectiva lo que necesita ser cambiado en nuestra sociedad. Los psicoanalistas pueden ver en perspectiva cómo las cosas pueden ser, no sólo como son, revelando las contradicciones de la conformidad social.

Palabras clave: Compromiso social, ética clínica, responsabilidad, Agit-Prop

This paper show us that a politically conscious practitioner has many possibilities to serve the community with a politically engaged way of life as person and professional. Mainly as an "active spectator" participating in the arguments of personal and social life, nor identifying with a hero but an agent. Using what the author calls "Agit-prop" art or enactment, and through a distanciation from the personal human drama we can see more in perspective what needs to be changed in our society. Psychoanalysts can see in perspective how things can be, not only as they are, revealing the contradictions of social conformity.

Key Words: Social Compromise, Clinical Ethos, Responsibility, Agit-Prop

English Title: Agitprop and Analysis: Politically Engaged Art as an Inspiration for Contemporary Clinical Practice

\section{Cita bibliográfica / Reference citation:}

Samuels, A. (2016). Agit-prop y Análisis: El arte políticamente comprometido como inspiración para la práctica clínica conmtemporánea. Clínica e Investigación Relacional, 10 (3): 750-762. [ISSN 19882939] [Recuperado de www.ceir.info] DOI: 10.21110/19882939.2016.100310

\footnotetext{
${ }^{1}$ Presentado en la Sesión Plenaria: "Vitality in Contexts of Destruction". Plenary IV: IARPP Rome Conference, June 11, 2016: THE ARTS OF TIME. RELATIONAL PSYCHOANALYSIS AND FORMS OF VITALITY IN CLINICAL PROCESS. Traducción castellana del original inglés facilitada por IARPP España.

${ }^{2}$ Psicoterapeuta, Profesor, Activista y Escritor. Profesor de Psicología Analitica - Centre for Psychoanalytic Studies, University of Essex (U.K.). Práctica privada como Consultor y Analista Jungiano. Presidente del United Kingdom Council for Psychotherapy en el period 2009-2012. Fundador del Psychotherapists and Counsellors for Social Responsibility. Profesor visitante en: Goldsmith's College, University of London / Postdoctoral Program in Psychotherapy and Psychoanalysis, New York University / City University of Macau. Fundador y Ex-miembro del Board de IARPP. Ha publicado más de 10 libros.
} 


\section{Introducción}

El propósito principal de esta breve charla es mostrar cómo mi trabajo clínico ha sido inspirado y desafiado por algunas prácticas del arte políticamente y socialmente comprometidos. Las inspiraciones y los desafíos pueden ser directos $y$, tan importante quizás, indirectos: sugerentes, heurísticos, como empujoncitos. Dicho arte lo he caracterizado, de manera absolutamente pragmática y sin rigor académico, con la etiqueta flexible de "agit-prop" (agitación y propaganda).

Como su título indica, la charla es acerca de qué es lo que "nosotros" --los analistas-podemos aprender y adaptar de "ellos" --los artistas-- en relación con determinados aspectos de nuestro trabajo. Después de todo, el arte bien puede ser una especie de terapia para la sociedad.

Soy consciente del peligro de idealizar al arte y a los artistas o de olvidar que no todos los artistas o movimientos artísticos son progresistas o de izquierdas en sus políticas. Creación y destrucción son gemelos, después de todo. A este respecto, cabe recordar al futurismo italiano y su postura acrítica hacia la industrialización, la guerra y el fascismo.

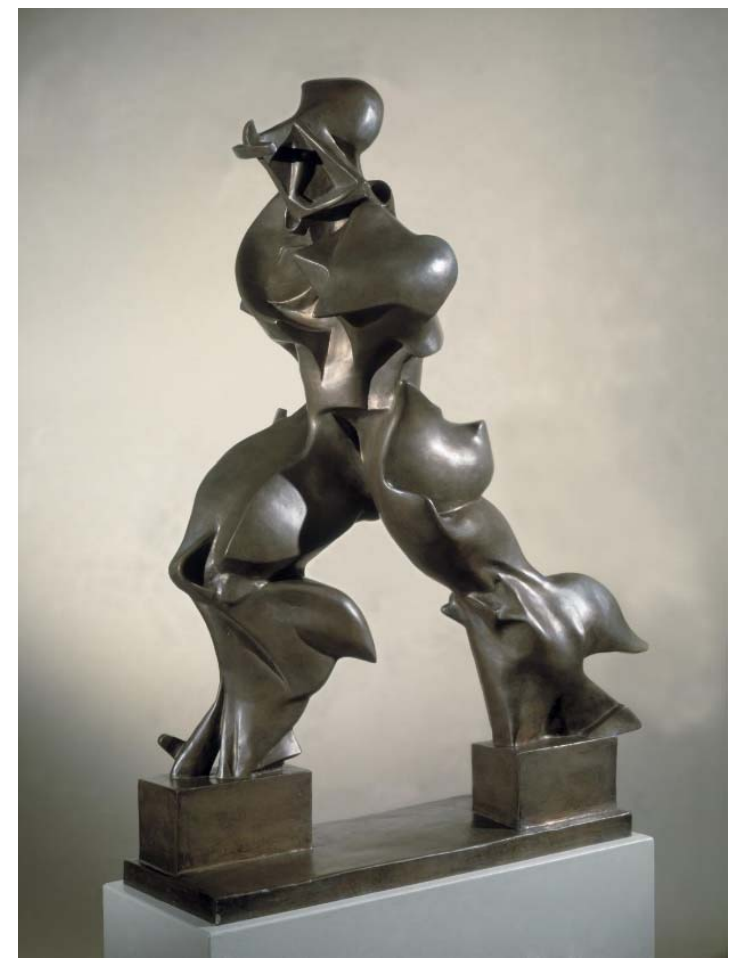

Formas únicas de continuidad en el espacio --Umberto Boccioni (1913) 


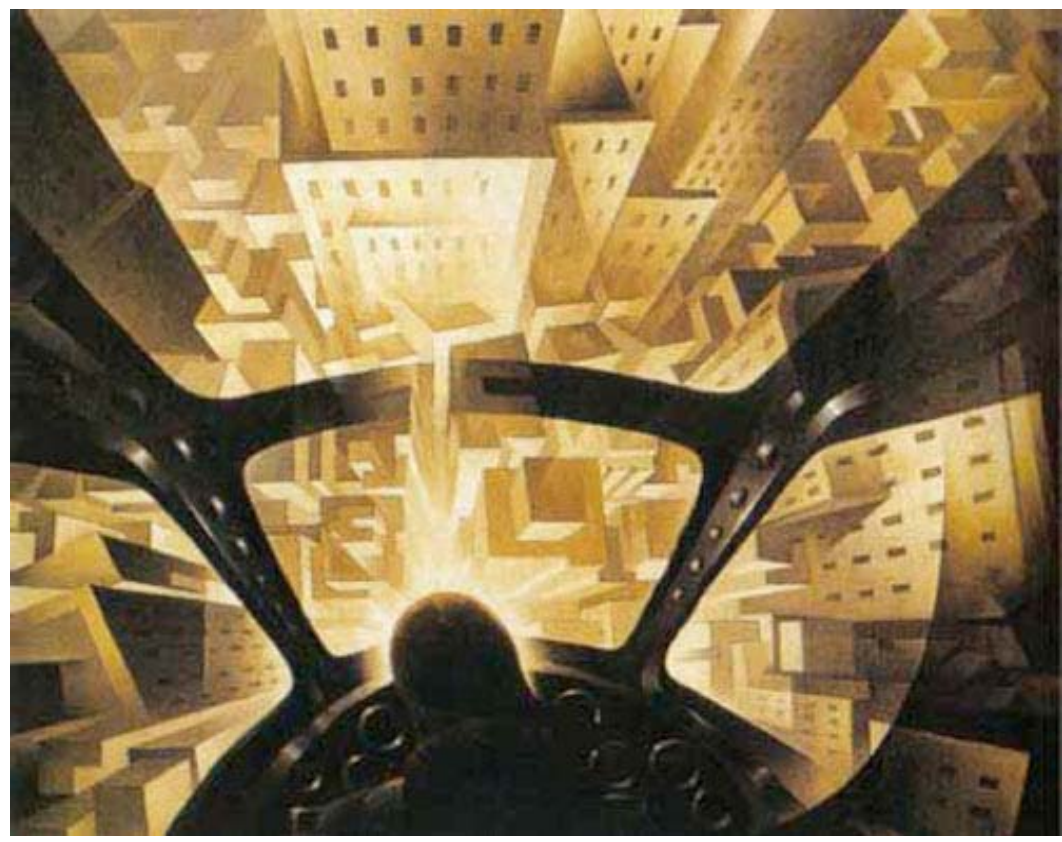

Vuelo en picado por la ciudad --Tullio Crali (1939).

A nivel personal, preparar esta charla me puso más en contacto con lo que he perdido y lo que he ganado al hacer la transición, desde dirigir un grupo de teatro progresivo experimental, hasta convertirme en un terapeuta hace cuarenta y cinco años.

El psicoanálisis y la psicoterapia en general son proyectos que están descubriendo (o tal vez redescubriendo) que son de naturaleza política. Dentro y fuera de la sesión, a menudo tratamos con lo que yo llamo "el político interno" (Samuels, 1993, 2001, 2015).

Sin embargo, nos esforzamos por encontrar formas de trabajar directamente en lugar de hacer interpretaciones simbólicas del material político, social y cultural que se plantea en el encuentro clínico. Buscamos satisfacer plenamente este tipo de material de una manera responsable y relacional (Samuels, 1993; 2006). Aquí, "los artistas" pueden ayudarnos.

Porque el hecho es que seguimos teniendo la experiencia de la mano muerta, la penumbra de las críticas de que esta Weltanschauung (concepción del mundo) no es analítica, y que el analista simplemente impone sus puntos de vista políticos al paciente. Cuando los psicoanalistas añadimos un "giro político" al "giro relacional", ¿no estamos actuando ultra vires, más allá de nuestra autoridad o responsabilidad como analistas?

Sabemos las respuestas a estos ataques, por supuesto, pero hoy no es el momento ni el contexto --o no hay la necesidad, tal vez-- de enumerarlas. Hoy es el momento de desarrollar ideas sobre cómo llevar a cabo el trabajo psicopolítico tan bien como podamos, un trabajo que una el espíritu de los tiempos con el espíritu de las profundidades. 
Por supuesto, el psicoanálisis no es el único en hacer el descubrimiento o redescubrimiento de una misión política latente. Por ejemplo, la teología de la liberación colabora con las sociedades reconocidas como injustas y destructivas a pesar de las críticas de la Iglesia como institución. Como también lo hacen los profesionales y teóricos de las artes a pesar de las críticas de los críticos que consideran sus resultados "aburridos" y una traición, y en consecuencia son penalizados etiquetándolos de "realismo social", sin nada que ver con el "verdadero" arte.

A partir de estas observaciones iniciales, hago un resumen de lo que seguirá:

(I) Primero, ver qué se puede aprender con el examen atento de una adaptación psicoanalítica de las teorías de la práctica teatral desarrolladas por Bertolt Brecht.

(li) Segundo, ver cómo la forma de pensar acerca del arte conceptual feminista se relaciona con lo que se experimenta en el análisis.

(lii) Después, iniciar una discusión acerca de lo que llamo "arte democrático" (como el de la Edad de hielo) y de cómo los fenómenos de este tipo transforman la comprensión de nuestras posibilidades clínicas.

(Iv) En la última sección se sugiere lo que el análisis podría aprender de la danza-escénica (Tanztheater), como la desarrollada por Pina Bausch en Alemania.

\section{Más allá de la empatía}

Se puede llamar "efecto de alienación" o "distanciamiento" o "extrañamiento"; en alemán, Verfremdungseffekt. Muchos de los estudiados intentos de Brecht para evitar la identificación empática por parte del público con los personajes de un drama parecen, a primera vista, ser totalmente ajenos a los valores y prácticas del psicoanálisis. La empatía es el activo de nuestro comercio, ¿verdad? ¿Se imaginan nuestras relaciones sin empatía ni identificación con el paciente? A buen seguro, ¿el "distanciamiento analítico" no sería una vuelta a los viejos tiempos de la neutralidad y la abstinencia? Discutámoslo un poco:

Brecht no inventó la idea del drama con conciencia social, pero desarrolló el teatro como un espacio para el debate social y político (Willett, 1959). El objetivo era cambiar el estatus y el rol de la audiencia para que diera lugar al surgimiento de un "espectador activo" participante de una discusión en lugar de la identificación con un personaje heroico.

En el teatro tradicional, la centralidad del ser humano individual se da por sentada. Pero, para Brecht, los personajes de una obra no son heroicos, sino personas normales en un 
contexto social implicadas en una narrativa episódica, a menudo expresada paradójicamente-- en lenguaje lírico.

Brecht desarrolló una serie de técnicas para llevar a cabo el distanciamiento, incluyendo el uso de pancartas en el escenario durante la actuación.

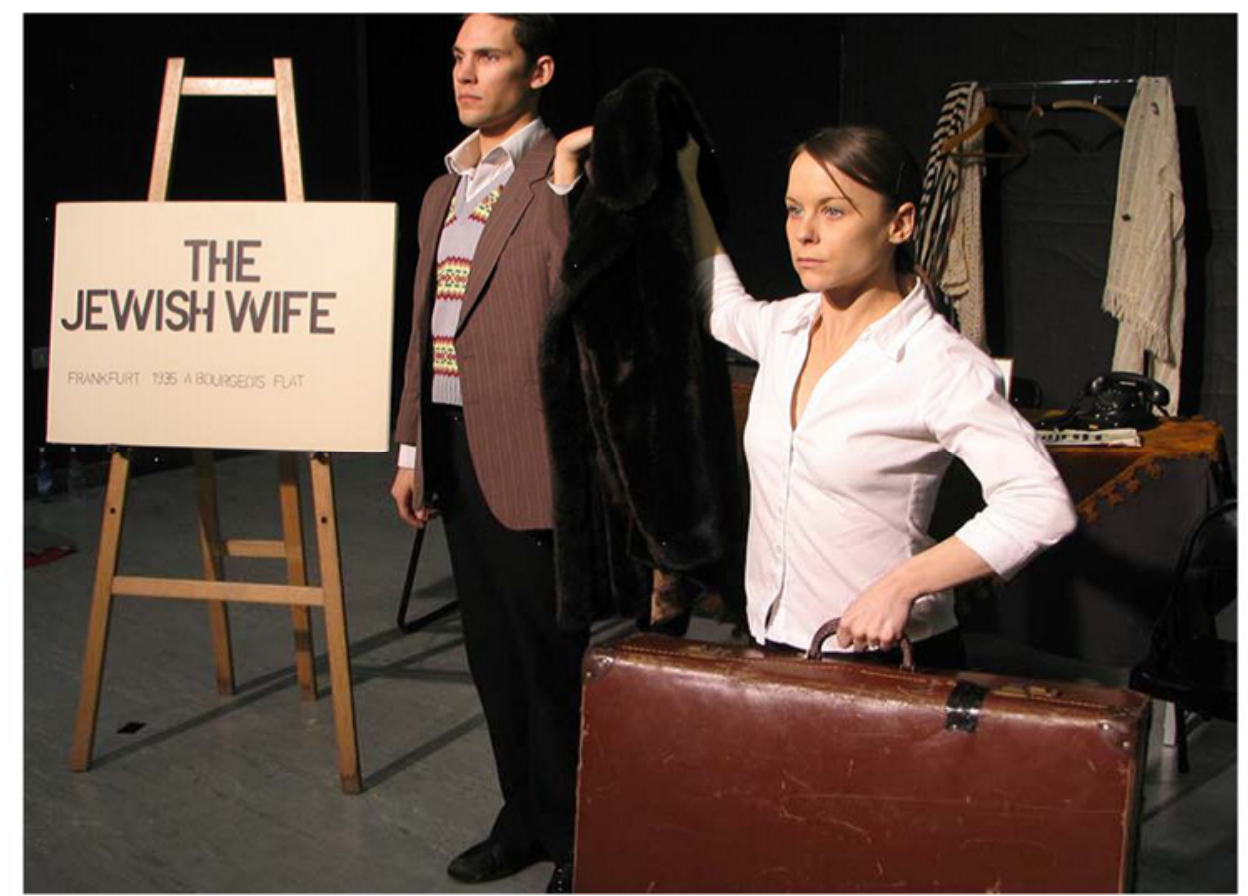

Del miedo y la miseria de Brecht del Tercer Reich, también conocida como La vida privada de la Raza Superior (1938)

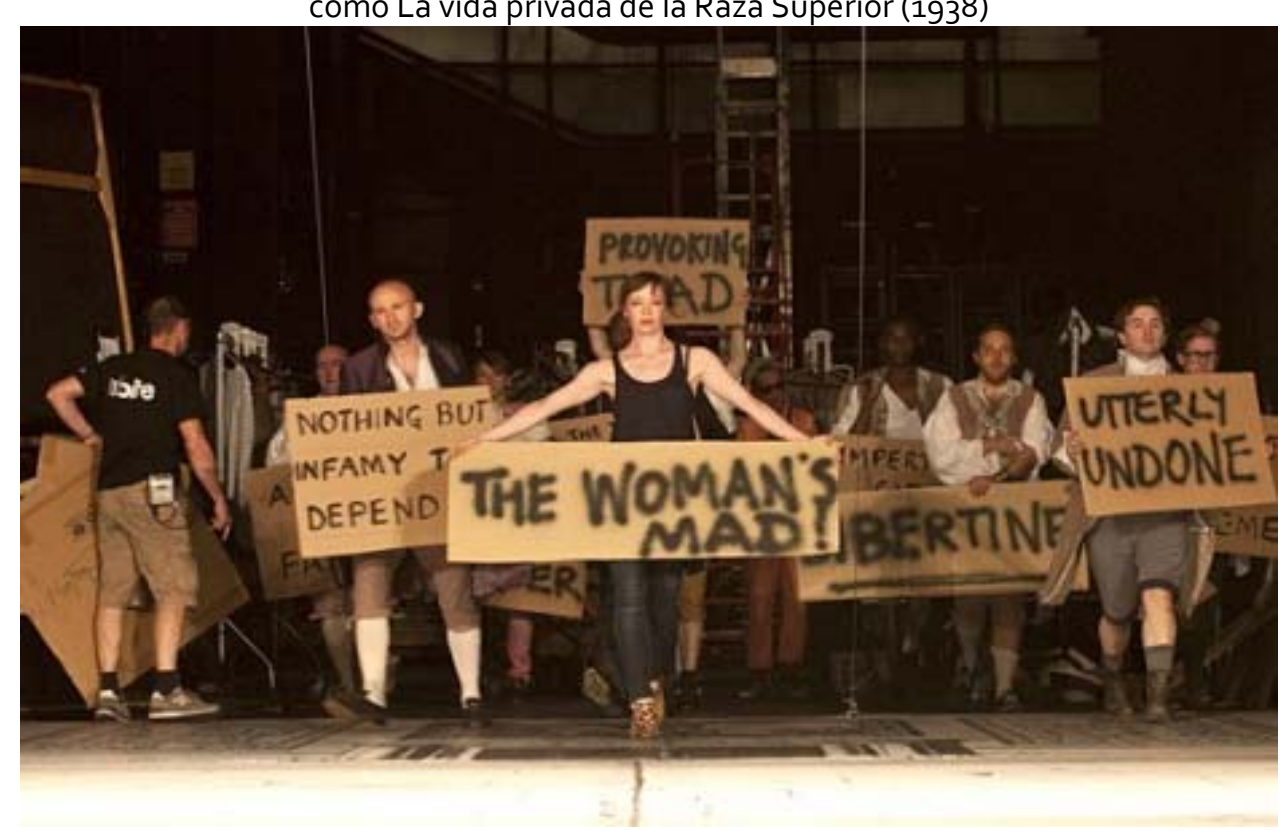

De La Madre de Brecht (1930-1) 
¿Qué significa todo esto para el trabajo clínico?

Lo que propongo es que las teorías de Brecht sobre la práctica teatral --alienación y distanciamiento en particular-- son incitantes e inspiradoras cuando las cuestiones políticas aparecen en el análisis. Si el paciente y el analista piensan juntos y discuten juntos (tanto si están de acuerdo como si no), todavía nos mantenemos en la esfera afectiva, seguimos contribuyendo a la vitalidad. La conexión y la función de distanciamiento son como dos polos del proyecto de terapia.

Mi sugerencia es que los pacientes y sus analistas relacionales comiencen a desarrollar procesos de "implicación hacia afuera", lo que significa colocarse fuera del juego de imágenes, afectos y procesos corporales que constituyen la relación terapéutica (o cualquier otra), a fin de que la pareja analítica pudiera, en algunas circunstancias (no todo el tiempo), revertir lo que normalmente hace y distanciarse (desengancharse) de la emoción. Hay que reconocer que esta sugerencia sobre el desprivilegio y replanteo radical del nivel de relación personal es bastante fuerte: el afecto, la emoción, incluso la intimidad en sí --todo se convierte en motivo de interrogación.

He aquí una breve viñeta clínica de "implicación hacia fuera" en la clínica. Yasmine es, digamos, egipcia, reportera política de televisión. He disfrazado su identidad. Vino al análisis con la esperanza de hacer algo con su virginidad a sus casi 40 años de edad. Ella eligió un analista hombre y judío. En el examen médico resultó que había un problema físico, así como algunos problemas psicológicos y aspectos culturales de gran profundidad y delicadeza.

No creo que pudiéramos haber elaborado las densidades emocionales y las complejidades culturales del interior de ambos --lo cual es fácil de imaginar, supongo, incluso sin decirlo-, si no hubiéramos sido capaces de dar un paso atrás desde el afecto y la empatía. Entramos, pues, activamente en una especie de discusión acerca de la fertilidad, la feminidad y la sexualidad, mezclada con la dinámica entre árabes y judíos. No denominamos a este flujo bidireccional didáctico de ninguna manera. Desde luego, no lo llamamos "implicación hacia fuera", ni tampoco fue ése el modo en que trabajamos todo el tiempo. Tal vez ninguno de los dos utilizamos pancartas, pero estuvimos muy cerca de hacerlo.

Lo que estoy introduciendo concierne al carácter engañoso del potencial de la dimensión personal: sabemos que a menudo esconde y lleva a una cuestión más amplia. Las ideas de Brecht son útiles para proporcionar apoyo a la elusión temporal de lo personal y resaltar la 
política. Sugiere al clínico: "Sigue la historia, sigue el argumento --no te quedes atrapado en el drama humano".

Bien. Examinemos ahora algunas prácticas artísticas feministas que podrían asimismo inspirar y desafiar al analista. (Sólo quiero añadir que, lo que dije sobre el análisis de influencia de Brecht, también funciona bastante bien en relación con la supervisión)

\section{Novias contra la bomba}

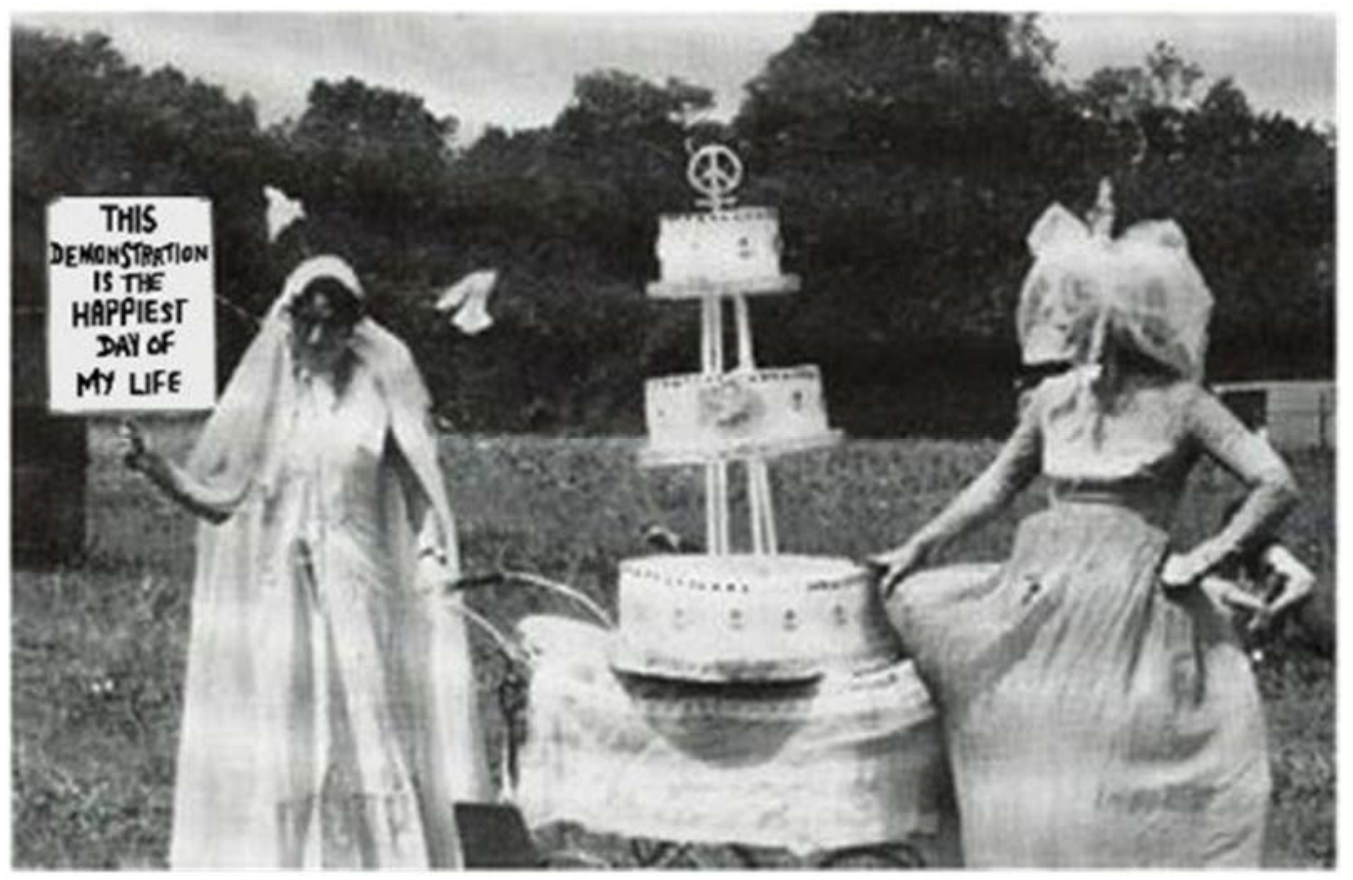

Novias contra la bomba - Shirley Cameron y Evelyn Plata (1983)

La imagen corresponde a una pieza de arte de performance feminista de 1983. Fue puesta en escena en una Campaña para el festival del Desarme Nuclear de Glastonbury en Inglaterra. ¿Es posible enumerar todas las cuestiones que alcanza a expresar esta única imagen condensada?. La relación de las mujeres con la esfera pública, las relaciones internacionales y la protección; el significado del matrimonio como el "día más feliz" de la vida de una mujer, la realización de un "buen matrimonio" con "un hombre del Ministerio de Defensa", como exponía el ensayo de catálogo para la performance; y más, por supuesto. En la performance, una mujer es casada con un misil: "Los misiles no son una necesidad, pero son parte de un mal matrimonio". 
En mi experiencia, muchos pacientes, no sólo mujeres, se encuentran a sí mismas diciendo cosas como: "Estoy casada con un misil". No hay que estimular o fomentar tales imágenes metafóricas: a veces la gente sueña con ellas, y puede ser difícil saber qué hacer con ellas.

Por eso me interesan las prácticas artísticas conceptuales feministas que, sobre todo entre 1970 y 1985 , han realizado una obra alquímica o trabajado con imágenes y experiencias de la vida cotidiana y familiar (lo que incluiría el pastel de bodas). Hubo un enfoque centrado en los acontecimientos ordinarios y los procesos del cuerpo de la mujer, tales como la menstruación o el dar a luz, mostrando cómo su naturaleza cotidiana era también algo a la vez especial, y especialmente conflictivo, y ello tanto a nivel individual como cultural (Parker y Pollock, 1987). ¿No es esto lo que los analistas quieren hacer --trabajar con lo sagrado ordinario, lo ordinario sagrado?

Por ejemplo, en el trabajo con muchos hombres, he encontrado que ocurre bastante lo mismo. El paciente masculino se da cuenta de los significados más amplios y profundos de su cuerpo ordinario. Esto puede afectar a todo lo relacionado con el engendrar y el ser padre, incluso cuando el paciente se encuentra en una fase de pre-padre, contemplando la paternidad. Del mismo modo, numerosos pacientes masculinos desean explorar sus sentimientos e ideas acerca del elegir no ser padre o no ser capaz de ser padre, cuando se supone que es justamente esto lo deseado.

Los hombres en las sociedades occidentales son agredidos por una batería de imágenes y narrativas acerca de la naturaleza maligna del cuerpo masculino, en contextos de abuso sexual doméstico o infantil. Es difícil encontrar imágenes que muestren a los "hombres" de una manera más positiva o al menos más matizada, por lo que sigue siendo problemático encontrar imágenes de erótica paternal benigna, que no degeneren en una idealización engañosa o en una caricatura.

Tal vez esta es la razón por la cual, en todo el mundo, de acuerdo con mi investigación, muchas más mujeres que hombres van a terapia. La masculinidad y lo que se percibe como vulnerabilidad son extraños compañeros de cama. Aquí presento una imagen no tan sutil desarrollada en nuestra campaña en Gran Bretaña para tratar de hacer algo al respecto. 


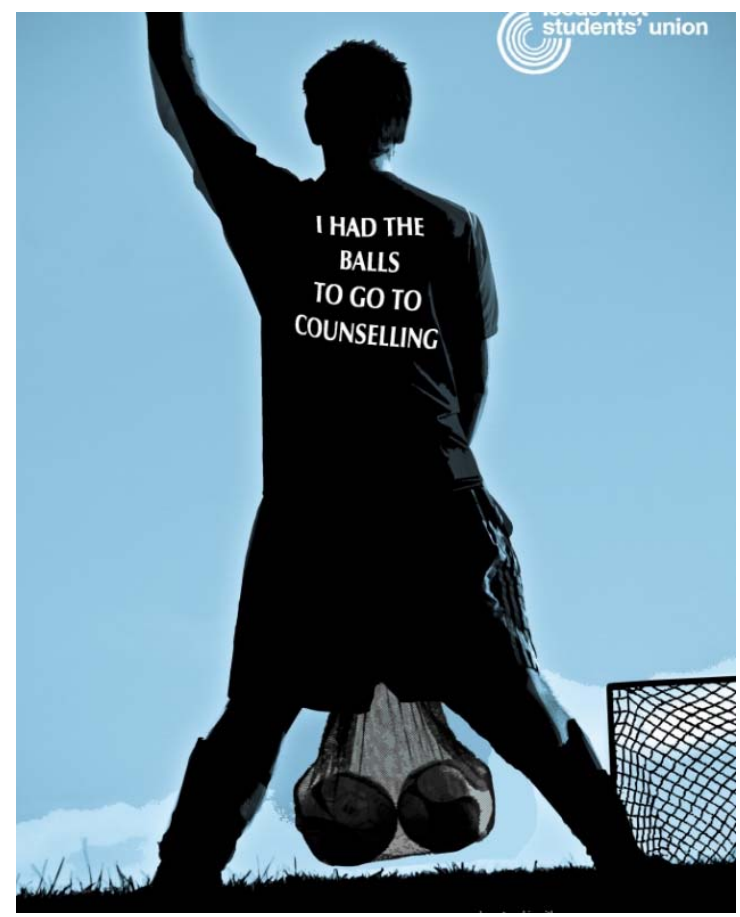

Tenía pelotas para ir a terapia (2014)

Después esta digresión contemporánea acerca de los "hombres" en terapia, en relación con las prácticas artísticas feministas, me centraré ahora en un tiempo muy anterior.

\section{Arte democrático, análisis democrático}

En esta sección, examinaré lo que llamo "arte democrático", con la idea en mente de un "psicoanálisis democrático". El objetivo sigue siendo el mismo: revisar algunas prácticas artísticas que puedan ser, ya de utilidad directa, ya de interés heurístico y sugerente para el clínico.

Es curioso como el psicoanálisis y las psicoterapias han excluido de su trabajo, tal vez sin darse cuenta, a un, llamémosle, lumpen-proletariado clínico, que incluye también a los pacientes de "difícil acceso". Muchos de esos pacientes son hombres, como decía hace un momento.

En la Edad de Hielo, hace 40.000 años, algo reconocible como arte apareció poco a poco en Europa. Era sofisticado e intencional, lo que implicaba una cognición altamente desarrollada y una imaginación aplicada. Los conservadores de las exposiciones (Cook, 2013) de dicha técnica se preguntaban: ¿por qué las personas empezaron a hacer arte? ¿Por qué dan forma a figuras que parecen mujeres y hombres? 


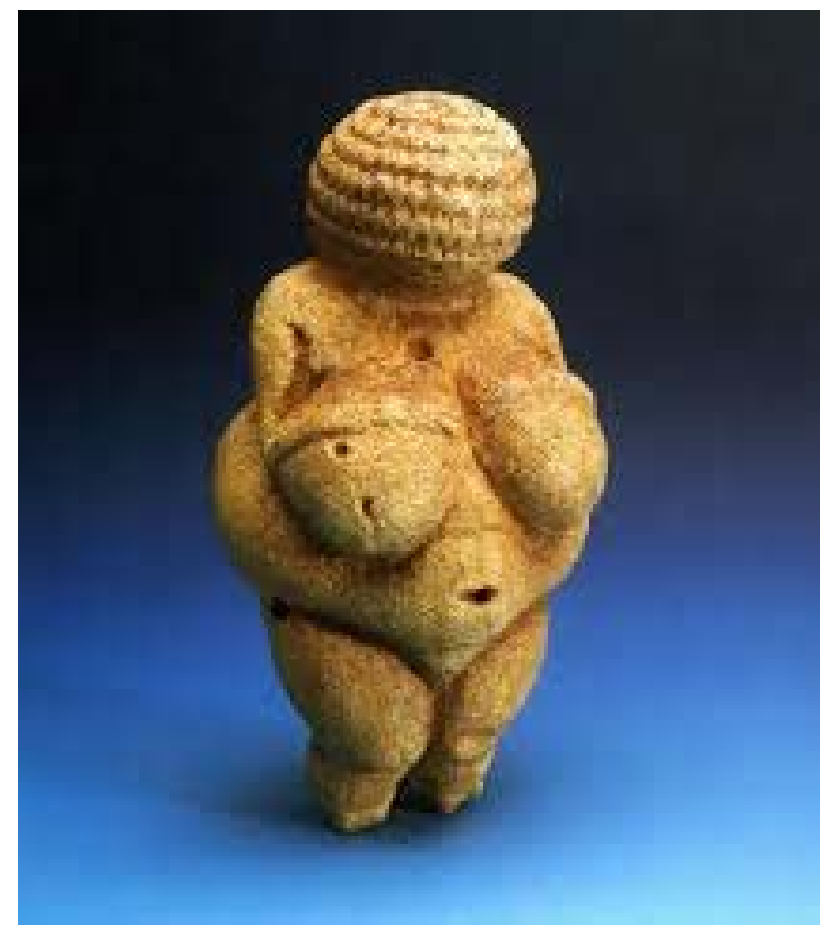

La Era de Hielo arte: la llegada de la mente moderna - 1 (mujer embarazada) (Museo Británico 2013) ¿Por qué registran sus vidas cotidianas?

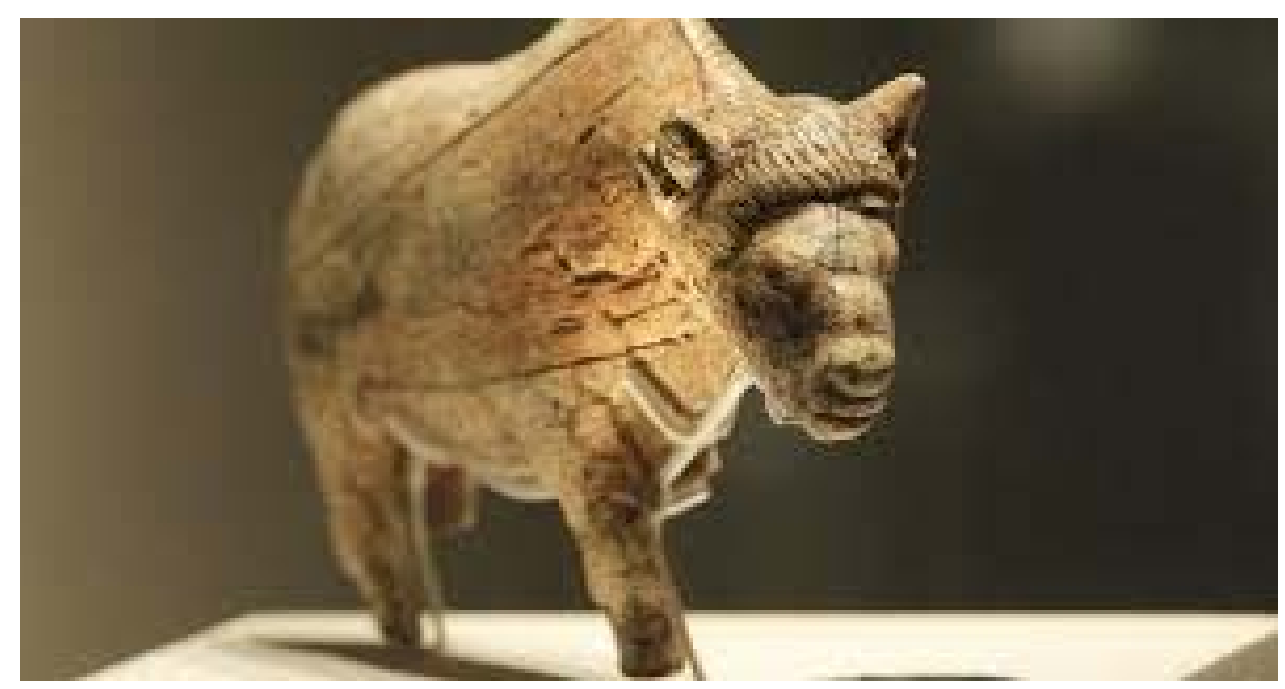

Arte de la Era de Hielo: la llegada de la mente moderna - 2 (animal) (Museo Británico 2013)

¿Por qué hacen un arte cargado de símbolos que no se basan en la "realidad", como el hombre-león de esta escultura?

\section{CelR Vol. 10 (3) - Octubre 2016 ISSN 1988-2939-www.ceir.info}

๑) Derechos reservados/Copyright de Clínica e investigación Relacional y los autores. Prohibida la reproducción total o parcial sin autorización expresa. Este material es para uso científico y profesional exclusivamente y puede contener información clínica sensible. Los editores no se responsabilizan de los contenidos de los autores. Dirigir las consultas sobre derechos y autorizaciones a ceir@psicoterapiarelacional.es 


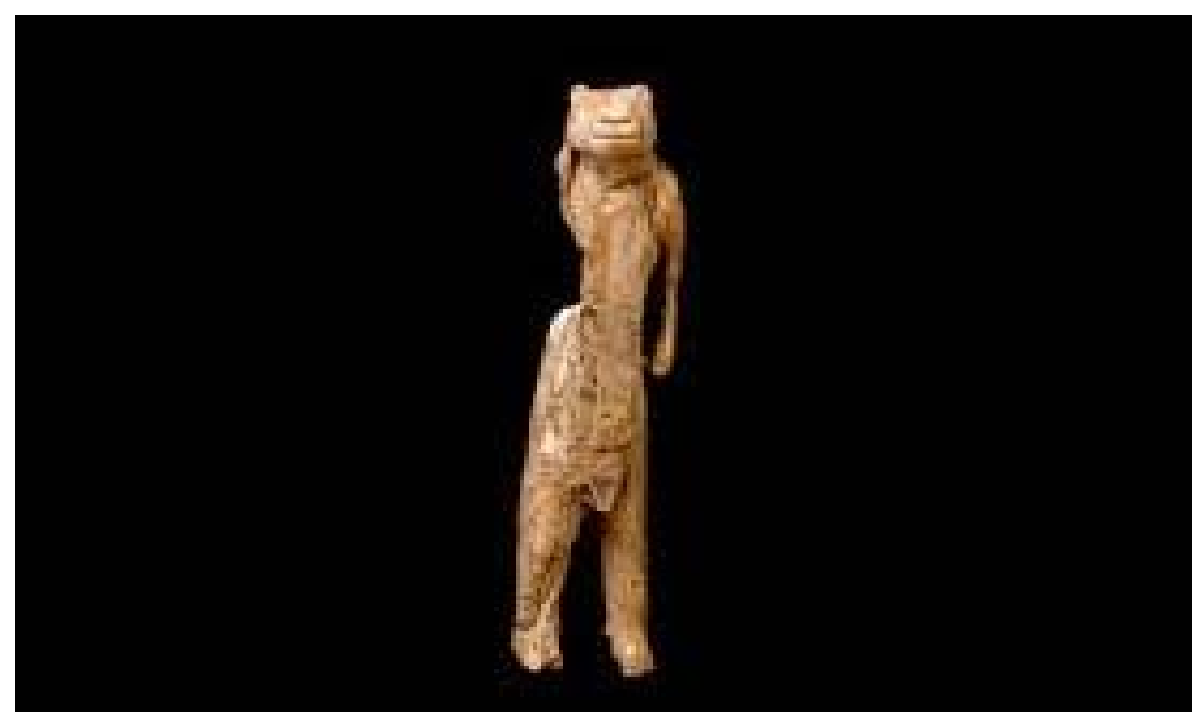

Arte en la Era de Hielo: la llegada de la mente moderna - 3 (Lion Man) (Museo Británico 2013)

Los seres humanos han necesitado hacer arte, al igual que han necesitado hacer religión o política. Mi sugerencia es que el paciente y el analista por igual pueden estar inspirados por el descubrimiento democrático de que la imaginación y la creatividad no están reservados a los Especialistas cuya cultura hace que les sea más fácil el "análisis". ¡El psicoanálisis no debería ser el equivalente de lo que es el 1\% del ámbito económico!

Esto presenta algunos desafíos acerca de la forma en que muchos de nosotros vemos nuestro trabajo. Valoramos la alianza terapéutica, pero, ¿podría asegurarse que no hay un elitismo secreto en este concepto nuclear? ¿Incluso algo esotérico? ¿Algo que reflejaría la micropolítica del poder y la jerarquía dentro del encuentro analítico? ¿Quién se considera, y por quién, que ha entrado en la Logia de la alianza terapéutica, donde el analista (supuestamente) ya está a la espera y a punto?

Lo que quiero es trazar un paralelismo con la profesionalización del arte, por así decirlo, desde la Edad de hielo. En aquel entonces, tal vez fue ritual, parte de la religión. De modo parecido, a pesar de sus raíces en prácticas de curación ubicuas, el análisis y la terapia están ahora profesionalizados, administrados por los miembros de la sociedad secreta de la alianza terapéutica. La historia del arte nos induce a cuestionar cada vez más profundamente nuestra exclusividad Masónica --nuestra déformation professionnelle (deformación profesional). 


\section{La relación en movimiento}

Para concluir, me gustaría compartir lo que he aprendido de la obra en teatro-danza de Pina Bausch y el Wuppertal Tanztheater. Bausch fue una gran Transmogrifier (transmutadora) artística y otra alquimista de la psicología y la psicopatología de la vida cotidiana que todos hemos experimentado en carne y alma: el anhelo de amor, el sadismo incurable, la imprevisibilidad loca y el desacuerdo de la mezcla de intimidad y aislamiento en la vida, y la jolie laide (hermosa fealdad) de la naturaleza del mundo. Los alquimistas siempre han olido el oro en la mierda y la mierda en el oro.

En este clip de un minuto, vemos algo de la circunvalación ritual y repetitiva de la agonía y el éxtasis de una relación, de cualquier relación. Vemos una práctica cenestésica enraizada en todo el cuerpo, en todo el ser, de los bailarines en escena. ¿No es ello también un emblema de lo que ocurre con las dos personas en el análisis, podríamos incluso decir de los dos artistas que hacen su análisis conjuntamente?

Espero que ustedes miren con sus cuerpos, además de sus ojos.

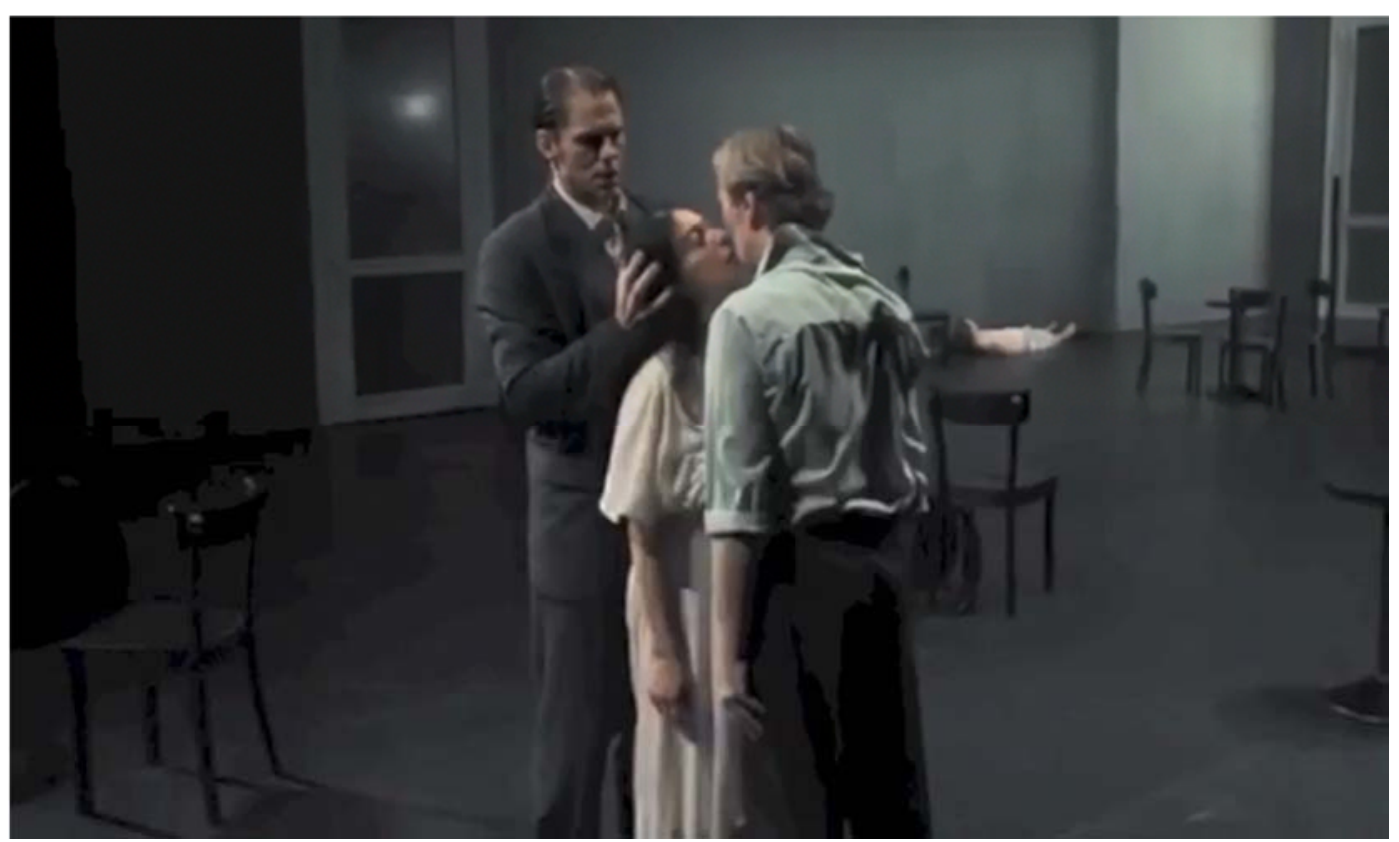

Escena del montaje de Pina Bausch, Café Müller (1978)¹

Concluyo con esta cita del divino Oscar.

"Ningún gran artista ve las cosas como realmente son.

\section{Si lo hiciera, dejaría de ser un artista"}

Oscar Wilde, La decadencia de la mentira (1889) 


\section{REFERENCIAS}

Bohart, A. \& Tallman, K. (1999). Empathy and the active client: an integrative, cognitiveexperiential approach. In A Bohart \& L. Greenberg (eds) Empathy Reconsidered: New Directions in Psychotherapy. Washington D.C.: American Psychological Association.

Cook, J. (2013) Ice Age Art: Arrival of the Modern Mind. London: British Museum Publications.

Jung, C.G. (1920) Psychological Types. Collected Works 6. London: Routledge and Kegan Paul (1971).

Hoffman, I. (2006). 'The myths of free association and the potentials of the analytical relationship'. International Journal of Psychoanalysis 87.

71).

Parker, R., Pollock, G. Framing Feminism: Art and the Women's Movement 1970-1985. London \& New York: Pandora.

Samuels, A (1993) The Political Psyche. London \& New York: Routledge.

Samuels, A. (2001) Politics on the Couch: Citizenship and the Internal Life. London \& New York: Karnac.

Samuels, A. (2006) Working directly with political, social and cultural material in the therapy session. In Psychoanalysis, Class and Politics: Encounters in the Clinical Setting. Eds Layton, L., Hollander, N., Gutwill, S. London \& New York: Routledge

Samuels, A. (2015) A New therapy for Politics? London\& New York: Karnac.

Willett, J. (1959) The Theatre of Bertolt Brecht. London: Shenval Press (1964).

Original recibido con fecha: 6-06-2016 Revisado: 30-8-2016 Aceptado: 31-10-2016

\section{NOTAS}

${ }^{1}$ El lector puede visualizar esta obra completa en dos versiones disponibles en la web, en Youtube y Vimeo https://www.youtube.com/watch?v=mxiWlgzb7r4/ https://vimeo.com/118644761 (El autor se refiere a la secuencia desde $26^{\prime} 10^{\prime \prime}$ a $27^{\prime} 50^{\prime \prime}$ en la versión de Vimeo) 